\title{
REFORMING URBAN SPATIAL MORPHOLOGY WITHIN SOCIAL SUSTAINABILITY: AN EXPLORATION OF PATTERN LANGUAGE OF MIDDLE EASTERN OPEN SPACES: SPACE OF BEIN EL-QASREEN, CASE STUDY IN CAIRO
}

\author{
G. MOHAMMED ${ }^{1} \&$ K. THWAITES ${ }^{2}$ \\ ${ }^{1}$ Urban design Department, Faculty of Urban and Regional Planning, Cairo University, Egypt. \\ ${ }^{2}$ Department of Landscape, University of Sheffield, UK.
}

\begin{abstract}
This paper explores a form of 'pattern language', which has entirely evolved within the framework of Islamic tradition, to illuminate the relationship between the ideological and physical dimensions of spatial morphology in Middle Eastern urban contexts, particularly Cairo and North Africa. The aim of this paper, therefore, is to highlight the indeterminate margin between the top-down and bottom-up conventional decisions and the role of each of them in reforming the macro and micro levels of urban forms. This form of pattern language maintained and protected social and urban sustainability by solving spontaneously the disputes and the pragmatic, chronic conflict between the top-down decisions represented in the central authority and their representatives such as professionals and the bottom-up decisions represented in the local residents. In this regard, this form of pattern language is conceptualised in a unified framework, called the anatomical approach, which is composed of two working models, an ideological model and a physical model. In this context, the paper will focus on the role of the ideological dimension in regenerating conventional decisions, whether top-down or bottom-up. Also it explores how the mechanism of decisions-making was operationalised via changes in the responsibility rules of different parties causing significant changes in the urban spatial morphology. This process has been conceptualised in the fine-tuning of the built environment. This pattern language, therefore, contributes to the planning education process by providing essential knowledge and a base for site analysis, the design process for urban spaces for professionals who have responsibilities for space management and urban conservation in contexts that have multi-layers of historic development.
\end{abstract}

Keywords: decision-making process, historic centres social sustainability, ideologies, Middle Eastern, urban and building conventions, urban morphology, urban open spaces.

\section{INTRODUCTION}

Examination of the spatial organisation of Middle Eastern historic city centres shows a more integrated relationship between ideological dimensions of city life and the physicality of city fabric. When city planning and design development separates ideological and physical dimensions, there is evidence to suggest that this can lead to detrimental impact on the well-being and the physicality of city fabric. Therefore, cities, particularly in the Middle East, have lost much of their quality of variety and the fine urban grain of their legacy that contributes to street life and vitality. The dense and varied rhythm of traditional buildings, spaces or streets are being replaced by larger residential and commercial developments that are imported from Western cultures. In this regard, a question arises: why and how did traditional cities sustain and survive throughout different historic periods, creating great beauty and lasting quality, without losing their functions and urban characteristics, whereas many modern cities and new developments often seem to fail to achieve this sustainability? The answer has been found notably, in historic city layouts, in urban fabrics that appear to be much more ideologically responsive and are in many ways a physical manifestation of the ideologies that were created to maintain social and urban sustainability.

This paper proposes an approach using a form of pattern language [1], as an analytical method of urban spatial morphology that is entirely driven by Islamic traditions. This approach uses two 
working models; an ideological model and a physical model. The ideological model focuses on the ideologies and values that lie beneath the physicality of the city or the physical model which is represented in the visual and physical configuration of the city fabric. This proposed pattern language tends to synthesise these two models in a unified frame work. Therefore, it deals with the spatial form in a way that it makes a cross cut underneath and through the upper layers of urban fabric. In this regard, the paper explores the different components of the ideological model and how it yields the aesthetical conventions that evolved from these values and ideologies of the physicality of the city. These conventions, that used to be as regulations and building laws of the traditional city and driven bottom-up or top-down, were activated and operationalised via different responsibility models. These models of responsibility are the second component of the ideological dimension [2]. Therefore, the role of the ideological model is to help us via its two components to redraw the image of the traditional built environment and its development, meanwhile the difference between it and the current situation in the light of the changes of responsibility models and their conventions. It thus explores how the urban forms of traditional cities survived, spontaneously contributing to the urban spatial morphology within social sustainability. This traditional image highlights the way for professionals, architects and urban designers, and academics with responsibility for management of open spaces who are involved in conservation processes. This method has been conceptualised in the finetuning of urban spatial morphology and responsibility models. In this regard, much is owed to the material of J. Akbar and J. Habraken. In their writings they emphasise the salient role of responsibility in the built environment and this will be explained later on in more detail. In the context, and for more clarification, the new concepts will be shown in bold italic and the conventions in italic.

\section{THE METHODOLOGY FOLLOWED}

The research has built up the conceptual framework of the proposed anatomical approach - pattern language - as a theoretical model, through two main phases. First, identifying the provisional ideological model and its two components, the tool to achieve social and urban sustainability which is the bottom-up and top-down conventions and the mechanism by which the conventional decisions were operationalised, which is the concept of responsibility. The methods used in this phase are a literature review of Middle Eastern writers such as J. Akbar and B. Hakim and Western writers like J. Habrakan, as well as well-documented case studies from North Africa and Middle Eastern cities and new concepts inferred from practice-based work in historic city centres in the Middle East and Palermo (Fig. 1).

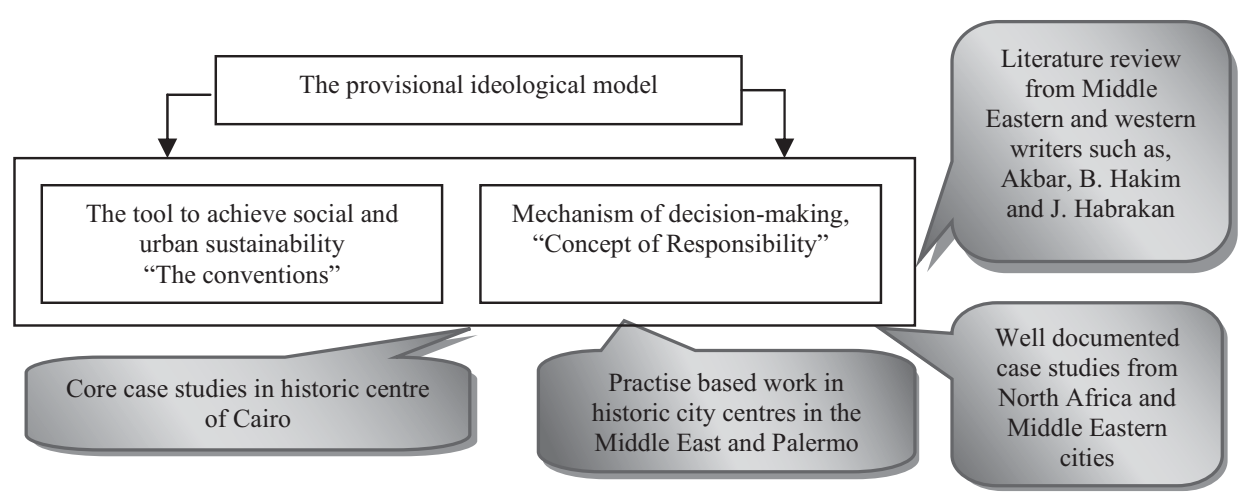

Figure 1: The two components of the provisional ideological model. 
Second, the application and case study phase. This will be by testing and applying the components of this provisional ideological model to the physical model via core case study site in traditional Islamic Cairo in Egypt. This will be through two applications; the application of bottom-up conventional decisions and application of top-down conventional decisions. In these two applications, observational data will be analysed using the following methods: maps, mapping of spatial use, historic photos, analysis of $19^{\text {th }}$ century painters who visited Egypt at that time, such as David Roberts (1796-1864), Pascal Coste (1787-1879) and Jean-Leon Gerome (1824-1904). This is in addition to the visual and graphical observational analyses.

\section{IDENTIFYING THE PROVISIONAL IDEOLOGICAL MODEL}

This phase will have three steps: first, the definition of anatomical ideological model and its influence on the concept of spatial development in the Middle Eastern cities; second, expressing the ideological values in the built environment and developing the two components of conventional decisions, bottom-up and top-down, and third, developing the second component of the ideological model, i.e. the mechanism of decision making, the concept of responsibility.

\subsection{Definition of anatomical ideological model and its influence on spatial development in the} Middle Eastern cities

The term 'anatomical', borrowed from medical terminology, is applied to this approach because it cross-cuts through multiple layers beneath the physicality of spatial form to explore the relations between these hidden layers and urban morphology [3]. The research to date has analysed the forces and ideological profiles that influence spatial morphology in Middle Eastern societies, especially those in Cairo and North Africa. It has investigated and analysed degrees of 'public-ness' and 'private-ness' as well as other socio-cultural, functional, political and religious forces [4]. It has sketched out religious, political and cultural aesthetic conventions and responsibility models that were responsible for the shrinking of open spaces over time. The Islamic perspective has traditionally viewed these open spaces under the supervision and control of the central authority as communal or vacant lands since there is no one was responsible for. That is because people are always interested in and pay more attention to what they own than what they do not. Hence, they do their best to maintain and protect any items belonging to them, such as their own shops and houses, more than other people's property. Consequently, the communist societies failed to persuade people to give priority to public ownership over private ones.

Theoretically, this explains that if the responsibility of any property in the built environment unified in one party that uses controls and owns, then it can be predicted that the urban fabric will be in the best situation in terms of maintenance, sustainability and private investment. On the other hand, lots of public spaces, streets which were considered as vacant land or leftover spaces, from the perspective of traditional built form, cause higher consumption of economic, public resources and public budgets in terms of maintenance and management compared with private ownership [5]. Therefore, Islamic jurisprudence pushed for unifying the responsibility for the properties of built environment in one person or private ownership than distributing responsibilities between different parties. As a result, public spaces 'waste lands' in the Islamic traditional city, decreased over time and this generated the leading concept of spatial development, which is 'spaces became corridors to link, not rooms to live' (Fig. 2) [3, 6]. This is to avoid wasting public resources. Importantly, these behaviours towards open space in the traditional built environment assisted the urban designers and architects to predict the future of urban morphology because they are not variable but are ideologically based on human instincts like ownership, control and dominancy, which are constant instincts. 


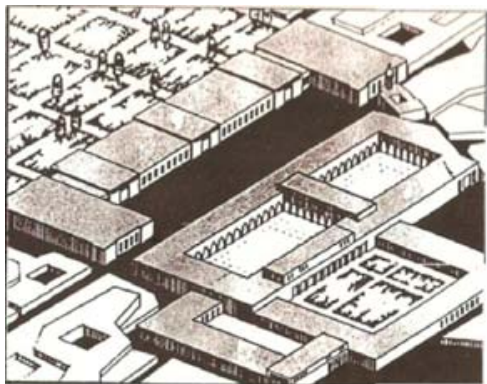

(a)

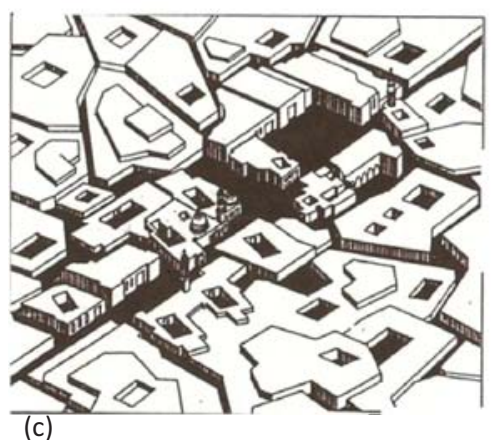

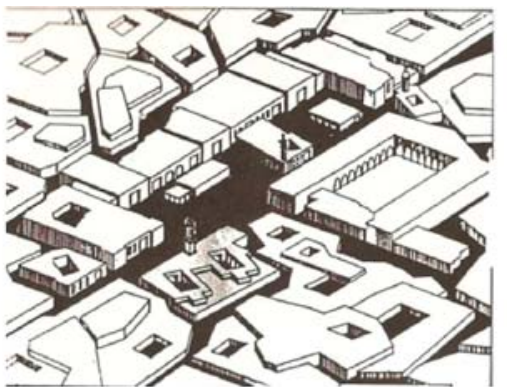

(b)

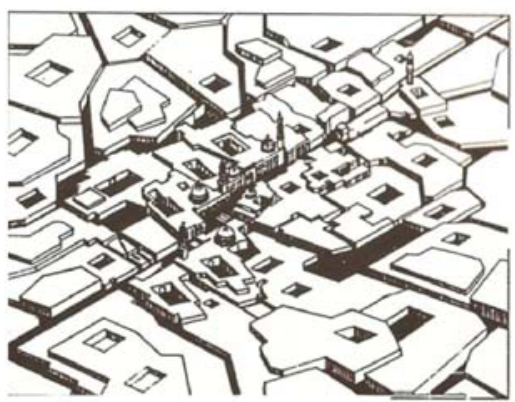

(d)

Figure 2: A macro-level view of the transformations and multiple layers of historical development in the urban centre of Cairo that clarifies the spatial development in the Middle Eastern context; 'spaces became corridors to link, not rooms to live'. (a) Royal space in the Fatimid period (A.D. 960-1170). (b) Military and educational space in the Ayyubid period (A.D. 1170-1250). (c) Commercial and educational space in the Mamluk Bahri period (A.D. 1260-1370). (d) Commercial and educational space in the Mamluk Burji and Ottoman periods (A.D. 1380-1830). Figures a, b, c \& d are by AlSayyad [7].

3.2 Expressing the ideological values in the built environment and developing the two components of conventional decisions, bottom-up and top-down

Comparative studies have demonstrated that Middle Eastern and Western cultures share a belief in society's progress. That is because both cultures have adopted the notion of progress through the engineering of society [8]. Most importantly, many Western development theories supported approaches and reflective processes of sustainable urbanism similar to those conventional processes in the traditional Middle Eastern Cities [9]. One difference between the two cultures, however, lies in Western culture's belief in human rationality, and in its ability to control progress. This determines appropriate solutions for well-being that are then manifested in the built environment that drives the top-down development of solutions. As a result, Western societies have increasingly refused to inculcate any directly religious values or principles including the environmental ones without filtering them through the lens of human rationality. Professionals in Western cultures therefore play a significant role in confirming the appropriateness of a given societal value, taking from individuals the responsibility for delivering these appropriate solutions. The obvious example is what happened with the block-long urban facades of many of the Amsterdam School apartment buildings dating from the 1920s and 1930s. Furthermore, a famous architect at that time participated in this scheme 
and confirmed the principle, saying 'it is better to design a bad plan with a good facade than a bad plan with a bad facade', echoed by other famous architects like H. P. Berage, K. P. C. de Bazel, P. L. Kramer and M. de Klerk. In other cases, the authority eliminates the role of individuals entirely as happened in the case of Hardouin Mansart, the famous architect, in 1686, when employed by Louis XIV to build a public square, [10]. This shift in roles, and the significant influence of professionals, clearly takes place in the transitional phase between ideological paradigms, such as the shifts from Marxism to capitalism, structuralism to post-structuralism and modernism to post-modernism (Fig. 3). Middle Eastern cultures, particularly those that are Muslim, have adopted a conceptualisation of progress that differs from that followed by Western cultures. Changes in political paradigms also occur in Middle Eastern cultures, but these changes remain at the edges of political regimes rather than forming the core belief that is seen as the basis for well-being. In Muslim communities, beliefs, rules and laws are inferred from the teachings of God, rather than based on human rationality [8]. These divine teachings are not solutions, but have constituted a set of principles and guidelines that naturally evolved to cope with human needs over time. The role of professionals and trade groups is accordingly embedded in the building process, and, with rare exceptions, there is no obvious professional intervention [11]. Instead, the role of professionals is to apply these core cultural principles, which underlie the sustainability of the social environment in Middle Eastern cities, to the built form in a collective and socially responsive manner that drives the top-down development of solutions, further described below. The religious, political and cultural ideologies applied to both Middle Eastern and Western cultures are therefore similar, but have slightly different forms and interpretations. For example, the idea of giving power to users of urban spaces through an ideological value such as the avoidance of harm has been accepted by Middle Eastern cultures but could be rejected under the precept of Western rationality. Western culture may only accept such an idea when values are applied in the built environment through the idea of control and management of spatial and urban morphology [6]. City councils and their representatives, including professionals and

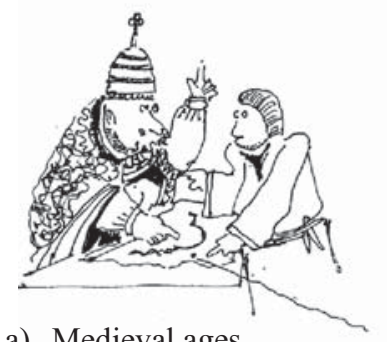

a) Medieval ages

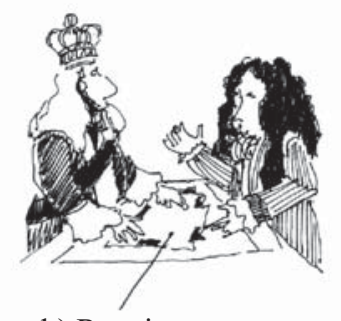

b) Renaissance

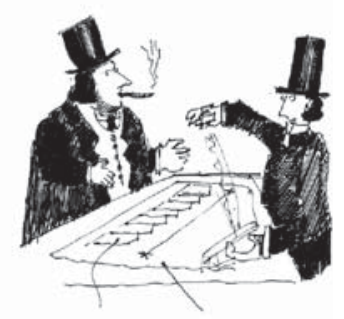

c) Industrial revolution

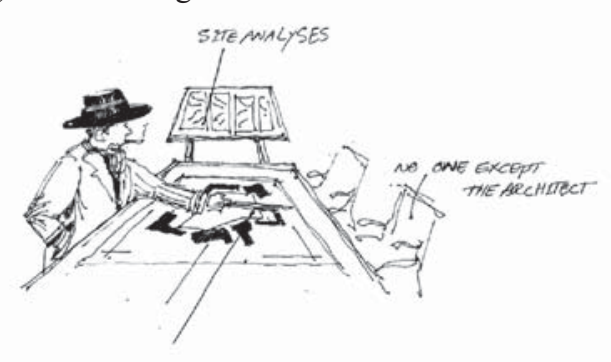

d) The first half of $20^{\text {th }}$ Century

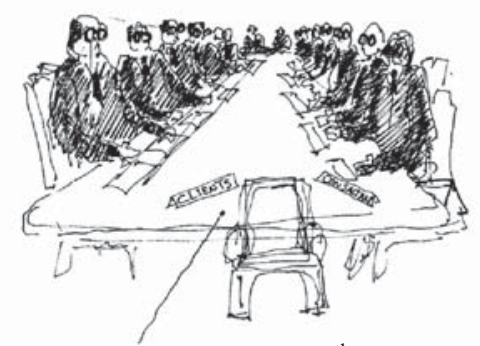

e) The second half of $20^{\text {th }}$ Century

Figure 3: The development of paradigms and ideologies throughout history, from divine teachings to human rationality in Western Culture. 


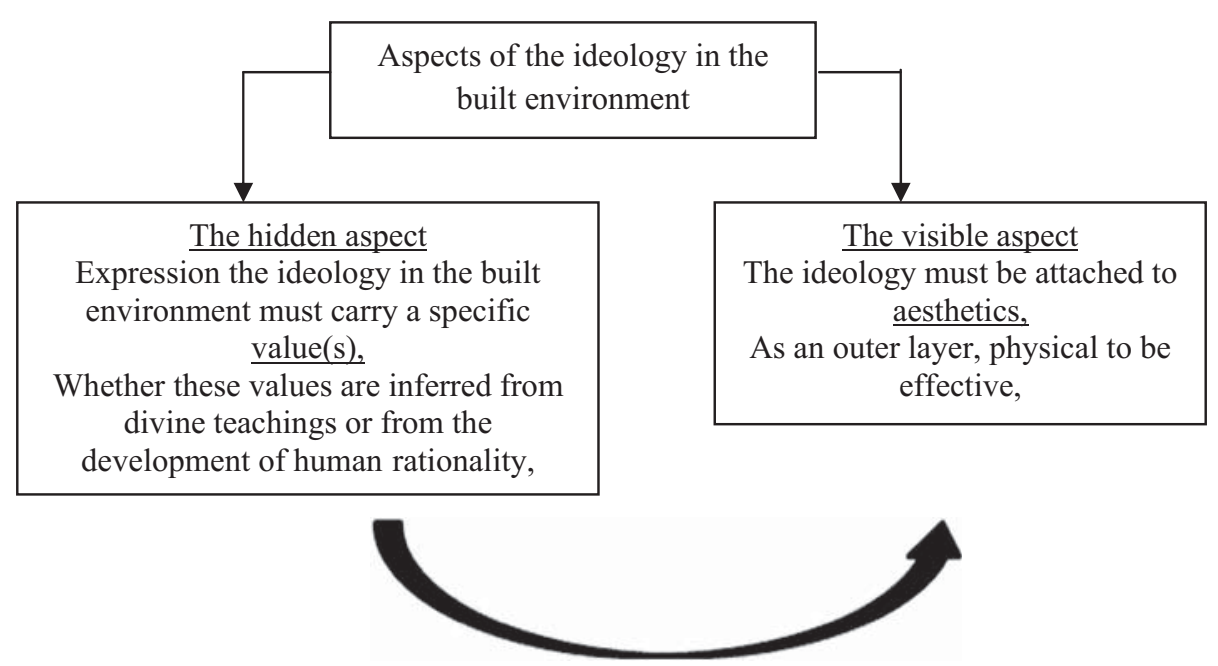

Figure 4: How ideological values have been expressed and have emerged in the built environment.

architects, take this power and responsibility from individuals, arguing that they are the only ones who can deliver good analyses and proper environmental proposals.

Accordingly, ideological expression in the Middle Eastern built environment must be attached to a core of specific value(s) as a hidden layer that is inferred from divine teachings. Meanwhile, the ideology must also be attached to an outer visible layer of aesthetic consideration to be influential [12]. On this basis, to create a socially responsive built form, architects and planners have to incorporate ethics with architectural and urban form in a unified and coherent context [13]. Hence, this aesthetic component must be physical and visible, something that people can feel and taste. It is pertinent to the concept of 'beautification', as applied to urban and building conventional decisions (Fig. 4). These conventional decisions that are the tools maintained social and urban sustainability of the traditional built environment were in two types; bottom-up and top-down conventional decisions (Fig. 5). In this respect, bottom-up represents the role of local residences in the building process without any authority's or professional's interventions except in the case of disputes between users or residents or severe cases of harm to others. Therefore the main source of these decisions in the traditional built environment, was a community-based customary rule system regulated by Islamic jurisprudence, whereas top-down conventional decisions represent the decisions taken by central authority or its representatives like professionals or trade groups in the building industry. Thus, it was concerned with producing public buildings on the macro-level of urban form to act, in some cases, as pilot projects organising and leading desired development in specific areas. Accordingly, this decision produced all official buildings and the bigger urban grains of urban form of the elites and ruling class. The main source of these types of decisions was Sufism [14].

On one hand, the development of values into aesthetical bottom-up conventions passes through three phases of spontaneous development. The first phase is the phase of emerging and expressing values to meet a specific Need. This starts when people begin to find out the solution for a specific need. This need may be controlled and inferred from religious, social, cultural or political values. Therefore many Eastern Scholars consider this as the base of the core of the traditional Middle Eastern building process, where people initiated their building's acts according to their needs [15]. Then begins the Creation step; people create a solution to convene that need. This solution refers to the 


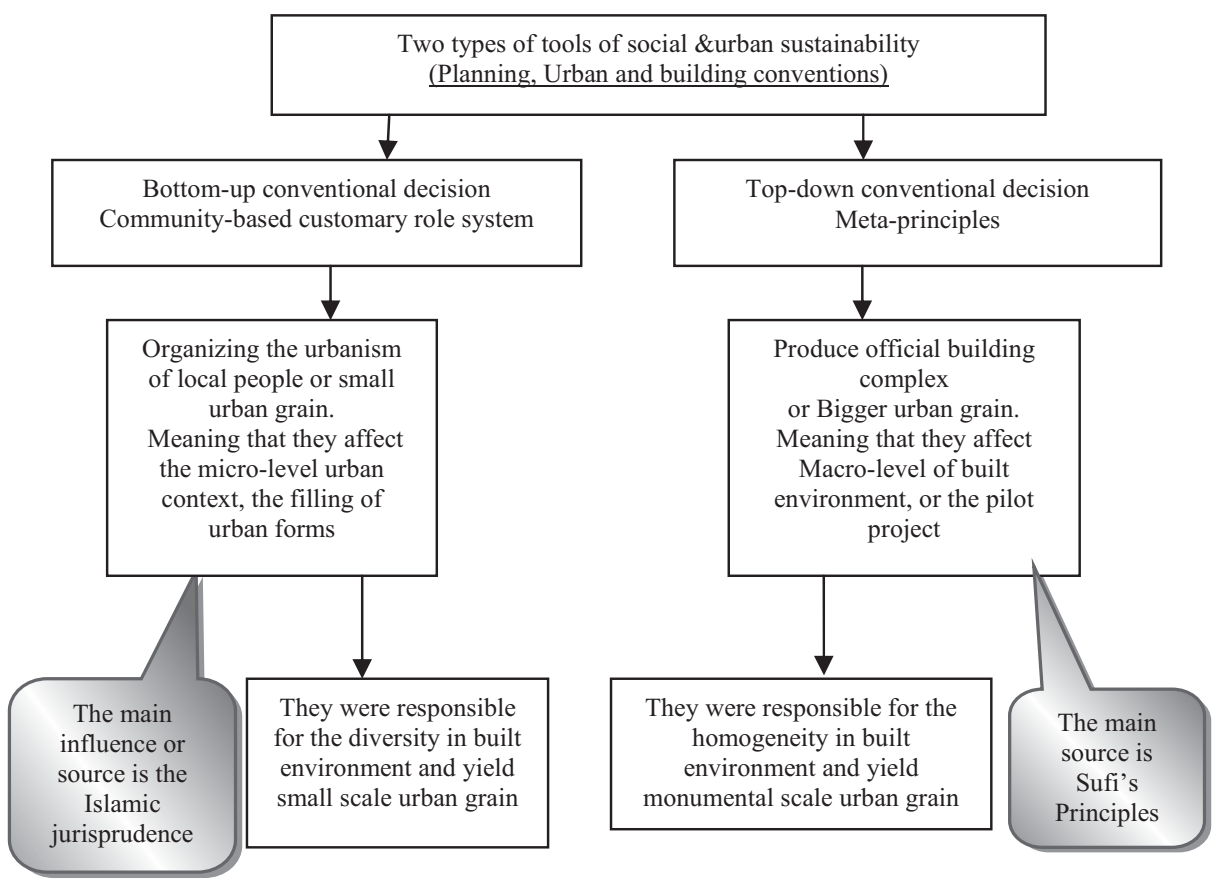

Figure 5: The two types of conventional decisions that regulated and organised the traditional built environment.

changes in the built environment. Over time, these solutions accumulated together to form provisional patterns. Therefore, this phase gives a value to any act added to the built environment.

The second is the tactical phase in which accumulative solutions that were created in phase one generated disputes or agreements that were responsible for refining these solutions to reach to the ideal example or the optimum one, which was then considered as a valid tested example. The tested ideal example is then widely used and becomes well known to be converted for use as a pattern. Therefore, this phase maintains spatial social sustainability.

The third is the aesthetical convention phase, in which, if the pattern proved and achieved success, it would gain validity and credibility as a stated law to be generalised as Urf, a convention (Fig. 6) [16]. On this basis, the conventions can be perceived when people manage their built environment without real professional intervention or through professional practice. Examples of these bottom-up conventions are those based on the sayings, Hadith, of Prophet Muhammad (PBUH): 'Not causing any harm to any users of space, by preventing harmful action or even managing to avoid the maximum harmful effect'. This saying 'Hadith' is considered as one of the most important guides or sources of all building conventions, regulations and laws, in the traditional Islamic built environment. The main principle to be inferred from this saying is the principle of avoiding harm, which generated all conventions that regulated the built form in the traditional city; for instance: 'Avoid harm to others and oneself. Accept the concept of interdependence. Respect the privacy of the private domain of others, particularly avoiding the creation of direct visual corridors. Respect the rights of original or earlier usage. Respect the rights of building higher within one's air space. Respect the property of others. Adjacent neighbours have the rights of pre-emption. Seven cubits is the minimum width for public through-streets (to allow two fully loaded camels to pass)., Avoid 


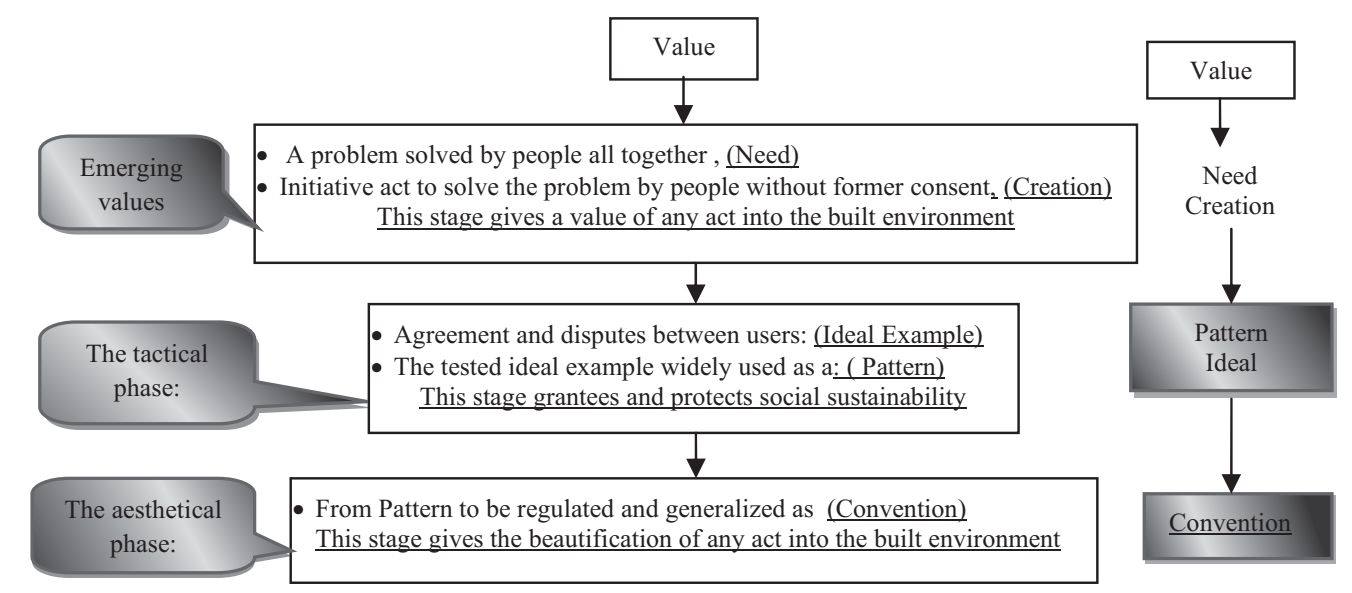

Figure 6: The regeneration of bottom-up conventional decisions in which values transformed into aesthetical conventions.

locating the sources of unpleasant smells and noisy activities adjacent to or near mosques' [17]. These types of conventions were responsible for the diversity all over the Middle Eastern regions, where each country has its own or local conventions that yielded the micro-level of urban form according to the local constraints, guidelines and regulations of each.

On the other hand, the development of top-down values into conventions followed a different route from that one of bottom-up. It passed through separate clear cut phases, not through a series of spontaneous developments. This process started with the charitable intention of the ruling class, notably the kings in the Middle Eastern Countries, to build multi-purpose buildings to be used for public services. This ambition spread to the professionals or trade groups, and this is the first phase. The second one is the recycling of materials and ideas. In this phase, the professionals tried to use the buildings of the precedents' works as a stock of building's materials. For example, they used the stones from ancient Egyptian temples, old mosques, complexes and also recycled the marble columns from dilapidated churches and walls. Also they used to take out windows and doors from the ancient buildings. This was as well as recycling of the previous valid ideas and examples following the same methods and design concepts. For examples they followed the same design pattern of the complicated labyrinthine bent entrance. The big challenge was the search for uniqueness against the existing powerful homogeneity of urban character. Therefore, this stage protected and maintained urban unity all over the Islamic region. Furthermore, in this phase, the Sufism had a significant influence on application of the traditional building convention to new buildings such as the convention of window Sitting Reciter. This - explained in detail later on - convention organized and controlled the monumental walls of official buildings and was responsible for allocating the different architectural elements in the architectural plan. Such elements are: the mausoleums, the prayer halls and the minarets. The third phase is the phase of public appeal. This phase is responsible for social sustainability in the built environment because the end product is an urban feature that was presented for public use. In another meaning it was like an unofficial vote against or for the new building. Two results were possible; first, if the building was rejected by people who behaved badly with the building or did not use it, then it would not be repeated, and from our contemporary view, it would be considered as a unique case. Second, if was accepted, then its ideas and material would be repeated and recycled thereafter (Fig. 7). 


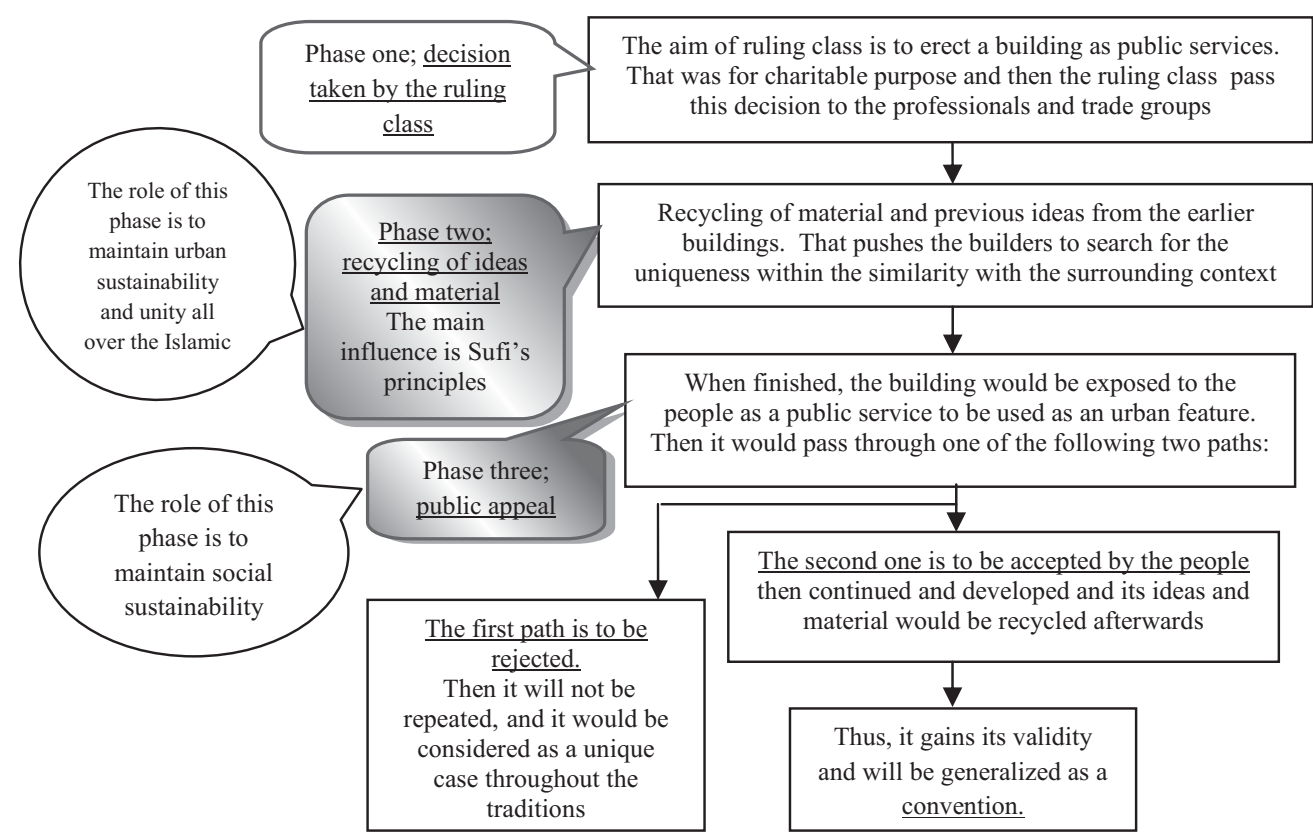

Figure 7: Regeneration of top-down conventional decisions in which values were transformed into aesthetical conventions.

These two types of conventional decisions achieved the balance between different parties and their responsibility distribution in traditional of the built environment in the Middle East. That is because the top-down conventional decisions were concerned with monumental buildings, meaning that they yielded the bigger urban grains, whereas the bottom-up ones were concerned with the territories of individuals. They thus regulated the smaller urban grains of building forms.

3.3 Developing the second component of the ideological model, i.e. the mechanism of decision making, concept of responsibility

The concept of responsibility contributes to a deeper understanding of the traditional Islamic built environment because it suggests a way of looking at the built environment as a process, not mainly as a product. Simply, it can be argued that responsibility is the perfect distribution of the rules between different actors in the built environment, or in other words the distributions of claims and rights ownership, use and control between the different parties in the built environment whether local residents or their representatives like professionals or trade groups, or the central authority and their representatives like professionals or trade groups. This distribution of responsibility was always followed by the action that the different parties were expected to take as regards the built forms according to their rules or rights. The distribution of responsibility thus helps the professionals and specialists to read the built environment in a way that will make the built environment's rationality predictable [2].

Generally, ownership enables a party to sell or to give without retaining use or control. The right of control is the ability to make changes and manipulate. For example, the employee in a hotel does not own the hotel, nor does s/he stay in any room, but s/he has the authority to change the position of the room's furniture [10]. This highlights that all acts affecting urban morphology like building 
walls, opening a window or a door, closing a street to traffic or changing the levelling and flooring of urban spaces reflect control rather than ownership. Furthermore, in many cases the party who owns is often in control. Moreover, the party who controls is always aware and up to date with the laws and regulations. The right of use is the enjoyment of the property without controlling or owning it. For instance, the person who rents a house from a landlord uses the house, lives in it, but does not control it. Sometimes one party has one, two or three rights, use, and control and own, at the same time. On the other hand, it is impossible for several parties to have the same right at the same time. Therefore, the synthesis of these three theoretical rights together yields six practical models of responsibility, and these have already been used in the built environment [8].

\subsubsection{Different models of responsibility}

Examination of the role of Islamic jurisprudence shows that these models illustrate the relations between the different parties in the built environment, describing the mechanism of generating decisions and how this informed and confirmed the role of each party. Second, some of these models were commonly used whilst the others were very rare in the traditional built environment. Consequently, these models of responsibility have drawn a complete key map for the properties and buildings and their status within the urban fabric. That means a building, for example, can belong to different models; the walls and the fixed structure are controlled by the owner, whereas the furniture is controlled by the users and the users can use walls without causing any changes. These models are as follows:

The unified model is only one party that has the three rights together. That means the party is fully in charge and such as a person owns a house and lives in it and of course, s/he controls any changes, whilst the dispersed model is the opposite of the unified one. In this type three parties share one property, the first one owns, the second one controls and the third one uses. The obvious example is endowment buildings. When someone, the first party, of the elite endows a property for charitable purposes, then the poor, the second party, will use and live in the building under the supervision and control of the manager, the third party. This model was responsible for - in the case of lack of maintenance - the deterioration of the buildings endowed in the traditional built environment.

The permissive model is that status in which the party who owns and controls gives the right of use to a second party; for example, the relation between the lessor or the tenant and the lessee. In this model, the two parties have to be in accord and communicate because of their relationship in the built environment. Additionally, this model always transforms to a type of unified one when the owner who controls gives more power to the user. When a person rents a house, s/he uses the house with permission from the owner, the contractor, who controls and owns. Also, the passageway may be used by passers-by and neighbours but it is controlled and 'owned' by the authority. Therefore, an easement right applies. The fourth one is the possessive model. In this model, one party has the right to use and control and the other party only owns. There have been many examples of this model. One of the most important examples is that of vendors who possess seats or specific areas in a market place. They control their place when they mark its parameters with their goods and moveable furniture but they do not own it. This relation is controlled and organised by the convention known as the right of utility.

The fifth and sixth models mainly give more power to the central authority over individuals. The fifth one is the trusteeship model in which one party controls the property and the other one uses and owns it: for example, the person who inherits a listed historic property from his/her family and still lives in it; this property is controlled by the central authority or its representatives but the person still owns and uses the property. This model was common in the traditional built environment. The sixth model is the temporary or the conditional model. This model was rare in the traditional built environment although it is popular in the contemporary built environment. It is concerned with the setbacks area. The party who owns has to leave a space, in the front or on the back, and s/he can use it without control. Alternatively, the owner cannot build in this area unless s/he gets consent from the controller, 
the authority; therefore it is conceptualized in conditional model. These two models, the fifth and the sixth, generates a stressful and costly relationship between the two parties as it requires employing someone to check the laws regarding these setbacks and this consumes the public budget. In the traditional built environment, this model takes a mortgage form as a first step, then transforms to the unified model by transferring the ownership to another owner.

\subsubsection{The role of these models of responsibility}

These models resolve the tension between top-down and bottom-up approaches by filling the gap between the two decisions of current urban design thinking through two main roles; the first role is to achieve balance. That is because they help to visualise a kind of balance in the extent to which 'top-down' and 'bottom-up' influences are active in such a way that the physicality of urban form is manifest. That is when they show where professionalised top-down interventions should gradually give way to allow room and opportunity for processes of bottom-up self-organisation to take hold (Fig. 8) [14]. The second role is identifying the nature of the indeterminate zone or the margin between top-down and bottom-up in different situations in terms of the six models of responsibility. Then the models begin to identify how beneficial change might be brought through the management of these models by fine-tuning physical, spatial structures and issues to do with the way that buildings and spaces are occupied, managed and controlled (Fig. 9) [14].

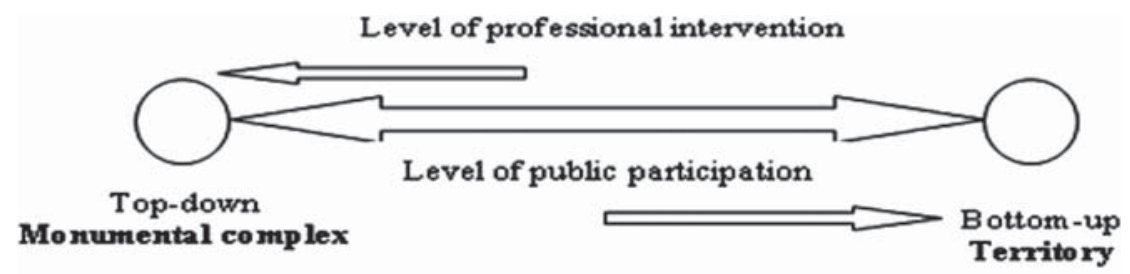

The balance

Figure 8: The balance between the two types of conventional decision making by the different models of responsibility.

\section{- Level of top-down or professional intervention in each model}

Unified model

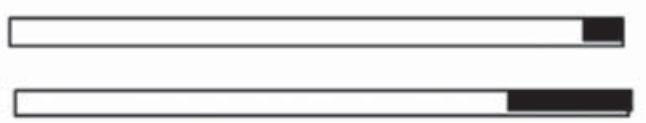

Permissive model

Dispersed model

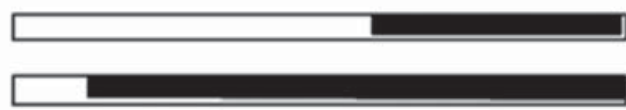

Trusteeship model

Conditional model
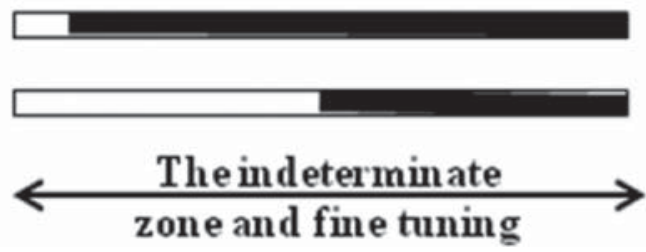

Figure 9: How the models of responsibility identify the indeterminate margin between top-down and bottom-up. 


\section{APPLICATION AND CASE STUDY PHASE}

In this section we will test and apply the components of the provisional ideological model to a case study in traditional Islamic Cairo. This will help us to redraw and rebuild the incremental growth of spatial morphology of traditional imagery and compare it with the current situation. The aim of this is to draw practical lessons showing how the top-down and bottom-up conventional decisions were operationalised within the mechanism of responsibility model to achieve the social and urban sustainability of the traditional built environment. The first case will be an application of bottom-up conventional decisions and the second case will be on top-down conventional decisions. These two applications will be applied to the historic city centre of Islamic Cairo, particularly the area called Bein El Qasreen, or the 'space between the two palaces' (Fig. 10). This case is chosen according to seven criteria. Firstly, this area started as a planned, powerful, formal and political area because it was built in the middle of royal palaces in the political centre of the city [18]. This space was also considered the most expensive and busiest space in medieval Cairo. Social and movement spaces overlap [19]. Furthermore, it was the place where the elite and high-ranking merchants lived and worked and it was also a public space. That means different royal families that ruled Egypt in different eras added buildings to carry their legacy confirming their political power. As a result, this space represents all the different historic eras of traditional Cairo, and therefore it has accumulated all the architectural and urban characters of the middle ages. Because of that the different models of responsibility are very noticeable. Importantly, this area is the best example of the concept of spatial development in the Middle Eastern cities: 'spaces became corridors to link, not rooms to live'.

\subsection{Application of bottom-up conventional decision}

The conventions of this type are inferred from Islamic jurisprudence based on the principles or Hadith of Prophet Muhammad - peace and blessing upon him - 'There is not to be any causing of harm nor is there to be any reciprocating of harm' [20]. Traditionally, the effect of the change of the responsibility models on the spatial morphology was more obvious than in the current situation. In front of the complex building of the king, El-Saleh Ayyub, it was a traditional market place, as shown in the painting by David Roberts and Pascale Coste (Fig. 11) [21, 22], meaning that the possessive model organised and dominated this space.

In this space, the transformation process started when the royal family and the political regime changed after the 1250 s, the new authority gave more power to vendors and pedlars. On this basis,

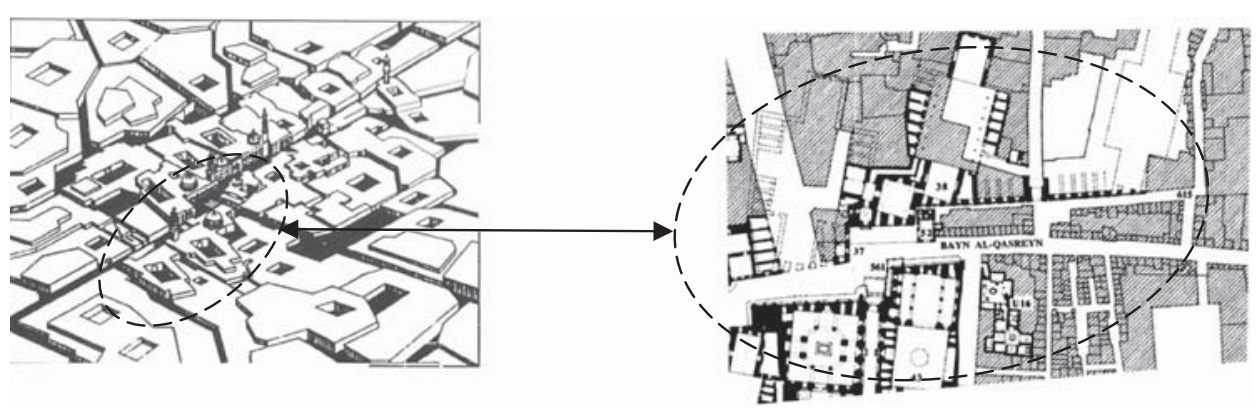

Figure 10: The case is the space of Bein El-Qasreen, 'between the two palaces', particularly in the front of the complex building of the king, El-Saleh Ayyub, built in 1240s, many traditional shops used to be as a traditional market place. 
a)

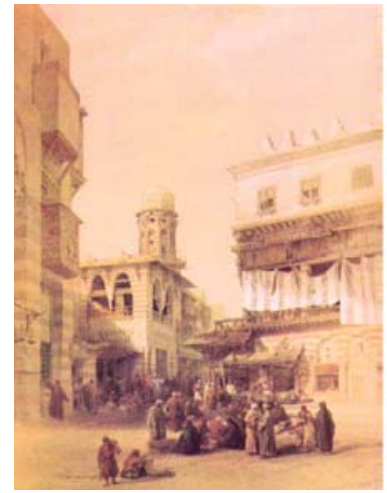

b)

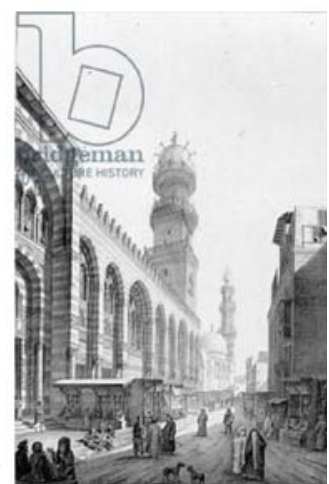

Figure 11: This painting ( $\mathrm{a} \& \mathrm{~b}$ ) of the space in mid-19 ${ }^{\text {th }}$ century in Cairo shows the right given to the vendors. They have the right to build or add a deck, or to shade them without blocking the space.

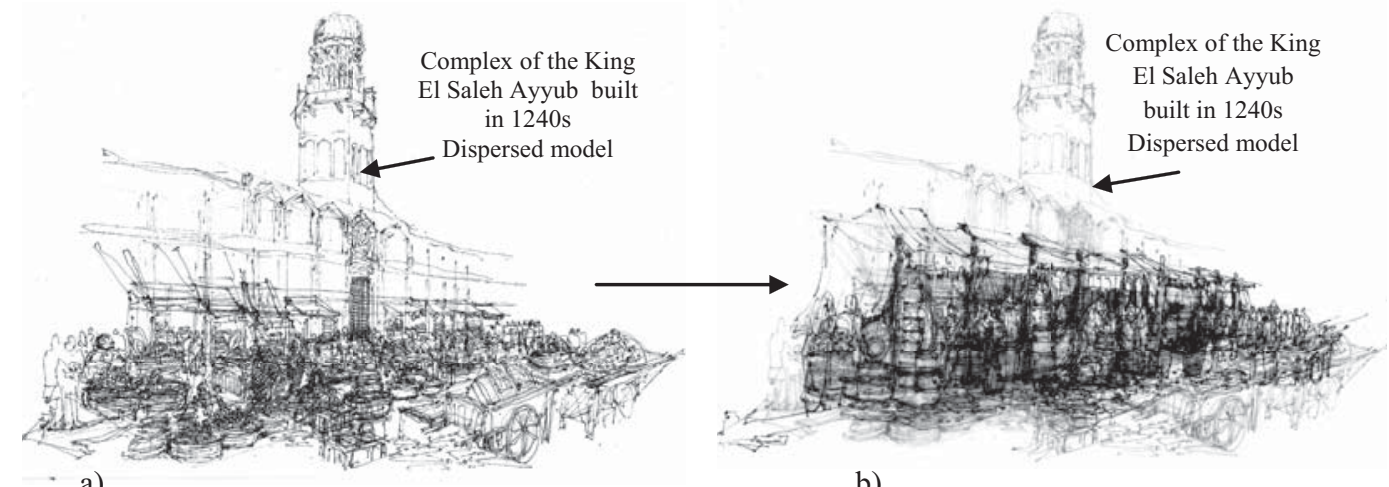

a)

b)

Figure 12: (a) During the 1240s and 1250s, the complex constituted the permissive model. This meant that it was under the control of the builder, who was the king and the royal family; the spaces in the front of this complex building used to be a market place. Therefore, vendors in this market place were allowed only to control their seats, only to utilise not to own (the possessive model). (b) After 1250s, and with the new political regime, the ownership status of complex building of King El Saleh Ayyub became a fully dispersed model and the new authority prevented any type of permanent structure. Meanwhile, the vendors had been given more power to control their places, thus they started to use light temporary structures to mark and specify their places and to build a shade (more powerful possessive model).

the vendors had the right to shade themselves without causing harm or encroaching on the neighbouring area but they did not have the right to erect anything that narrowed or blocked the passageway (Fig. 12). Moreover, the places attached to vendors places, in the front of mosques and official buildings are possessed by the vendors, and therefore they had to follow the top-down regulations that governed these places (Fig. 13) [23]. Issuing laws by the authority or its representatives was considered as the most obvious aspect of this model. This was to minimise and organise the control of the 


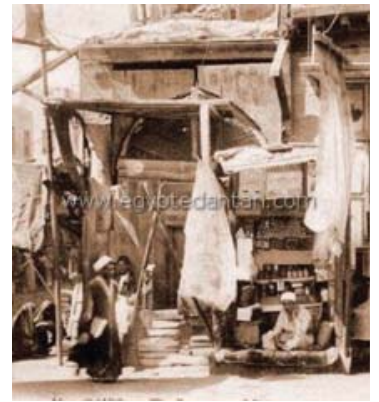

a)

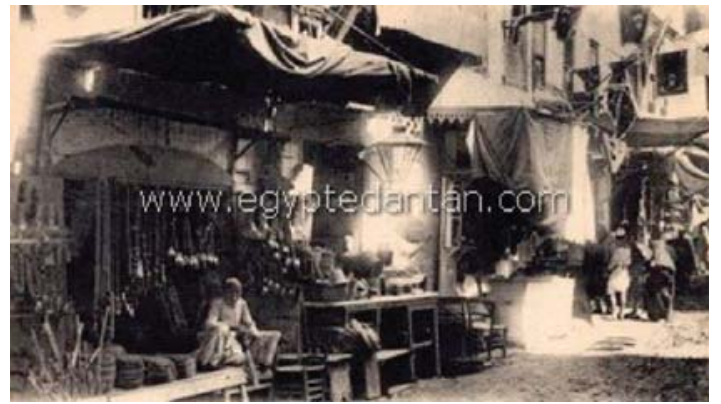

b)

Figure13: Photos (a \& b) are for the space at the end of 19th century in Cairo and show the rights and claims given to the shop owners. They had the right to build or add a deck, or to shade them without blocking the space. That caused the moveable active edges of space. Source: www.egyptedantan.com

user and disputes between vendors. That outlines the stressful and tense relationship between the user and the owner and demonstrates the no man's land; sometimes this area was dominated by user control, sometimes overwhelmed by owners' laws, a tug-of-war between the two partners. The role of the other party who controls 'the authority' was to reform and organise this competitive behaviour between the users through solving disputes. That means interventions by the authority were limited because these disputes were solved first by negotiation 'conventions' between the users. The conventions controlled and organised each party's act as follows; for the vendors' seats the organising convention was the right of utility which called for the precedence of vendors who came first to utilise and claim a specific area in the market place to put their products without blocking the passageway. For the passers-by the organising convention was - No causing of harm, which called for the freedom to use the space and to exercise their rights properly without descending to or abusing others' rights. This was in addition to the right of objection by the passers-by to any harmful act of the vendors.

Gradually, with the growing power and control of the vendors the light structures transformed into fixed shops with permanent ceilings. Thus the market place transformed step by step into shops and the vendors became shop owners, meaning that the responsibility model moved gradually from the possessive model to the unified model (Fig. 14).The conventions controlled and organised each party's acts as follows: for the shop owners and local residences the organising convention was 'no causing of harm or avoidance of maximum harm', which calls for the freedom to act or build in the horizontal or vertical dimension of space provided they did not cause obstacles or block the space visually, orally or physically. For the passersby the organising convention was the avoidance of harm which calls for the freedom to use the space and to exercise their rights properly without descending to abusing others' rights. This was in addition to the right of objection by the passers-by to any harmful act of the vendors or shops.

The current situation started at the beginning of the 1950s. The area was listed as a protected heritage site; accordingly, the central authority withdrew the right of control from the shop owners who could claim only the ownership and use, meaning that the model moved again to the trusteeship model. Therefore the trusteeship model is the dominating model in the space at the moment. This means that the shop owners cannot display goods or block the passageway; in turn, the edges of space transformed from moveable, 'dynamic', active edges into static edges (Figs. 15 \& 16). Thus it 


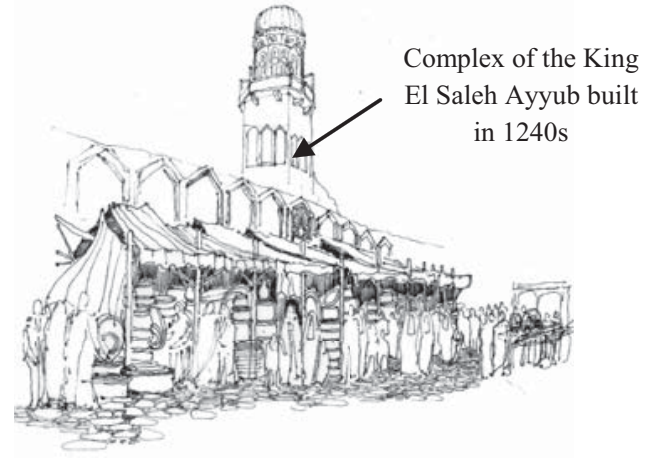

a)

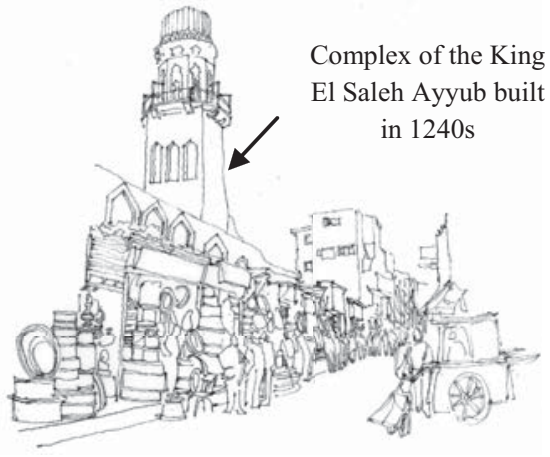

b)

Figure 14: a) The complex building became the dispersed model and the authority prevented any type of heavy, fixed or built-in walls to be attached to the building. Therefore, the vendors started to increase the level of control they had, then they transformed their temporary shade structures into permanent light structures, provided that it caused no harm or straddling the passageway of people. It then began to be used as a unified model and they nearly owned these seats (they could give these places to their descendants but could not sell them to others). b) Over time the vendors started to rebuild their light structure to be as new fixed permanent structure attached to the original edges and walls of buildings. That means, the vendors gained more power and increased their rights and thus they owned their places. The vendors became shop owners, and the places and seats became built-in shops with fixed structures, the unified model, as a result, the space transformed into a thoroughfare.

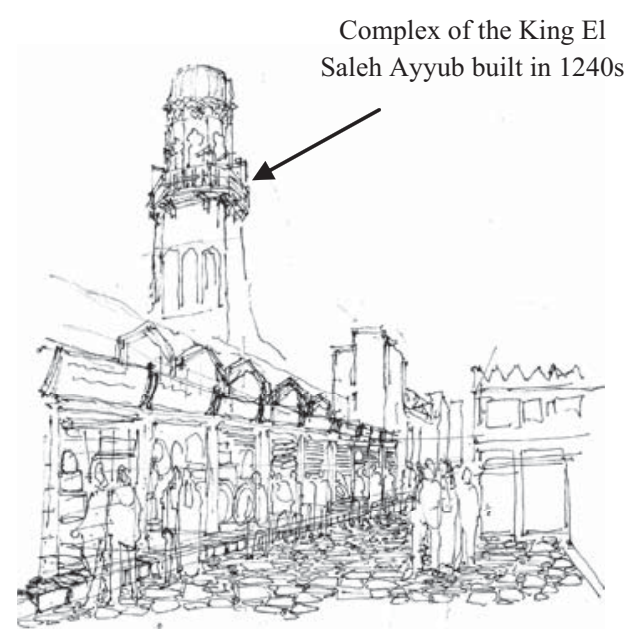

Figure 15: Static spatial edges of the trusteeship model. The shop owners are not allowed to display their products outside their shops. 


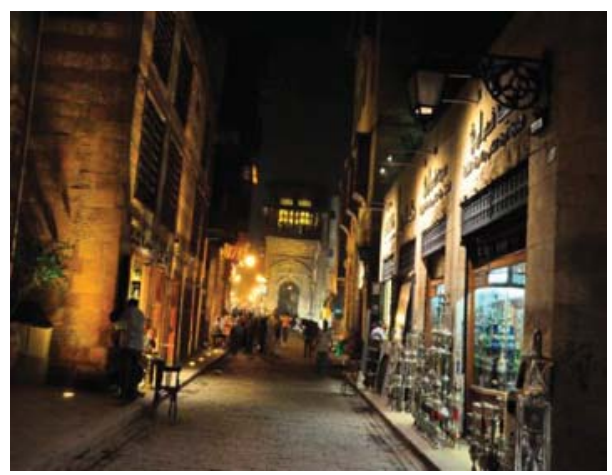

Figure 16: The current trusteeship model forbids the building of decks and blocking the passageway with displayed goods;

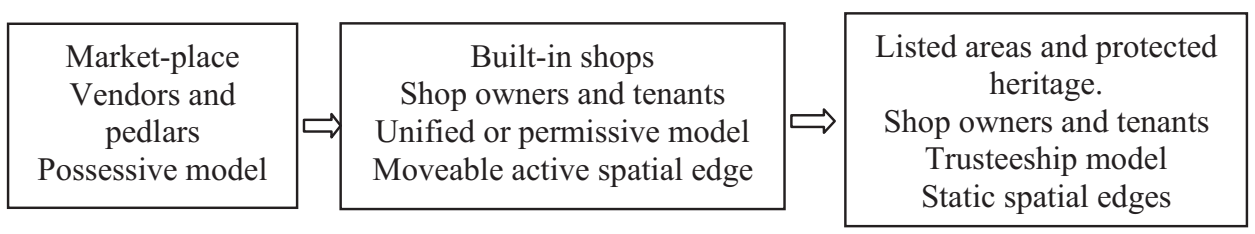

Figure 17: The change of spatial morphology because of the change of responsibility model.

can be concluded that the change in responsibility model dramatically affected the transaction sphere and, in turn, the inner space. Therefore, it can be concluded that spatial urban morphology changed dramatically as a result of the change of responsibility model (Fig. 17).

\subsection{Application of top-down conventional decision}

The conventions in this type of decision are mainly drawn from Sufism and are concerned with creating reciprocal relations between spatial walls and edges and the users or the passersby, or in other words between the dead load of spaces, fixed and built-in structures, and live load of spaces, moveable and light structures $[3,6]$. This mutual relation became more prominent in the dispersed model of responsibility in which rights and claims were distributed between three parties. Furthermore, this model was the key organiser of the charitable system, the Waqf (endowment). Therefore, the elite endowed buildings seeking to do good deeds for religious charitable purposes. The significant impact of this relation is that it created and reformed the edges of spatial form in an interactive mode. In this regard, there have been two types of mutual relations that are conceptualized in interactive edges [14]; the first one is the religious mutual relation. It is apparent in the mausoleum of the kings or ruling class in the busiest areas within the city. The second one is functional and religious. It appears mainly in specific types of endowed buildings called Sabil or public fountain (Fig. 18).

\subsubsection{The first relation; religious mutual relation; the interactive edges between the Mausoleum} and the passers-by

Traditionally, this relation was considered as one of the most important social patterns of daily life. The basic principle of this relation is derived from Sufi's principles that were operationalised in the 
Two types of mutual relation or interactive edge

These are the reciprocal relation between the building and the passersby and they used to be an essential pattern of the traditional life of the community. They are now no longer used. They were responsible for the social maintenance system called the Waqf (endowment).

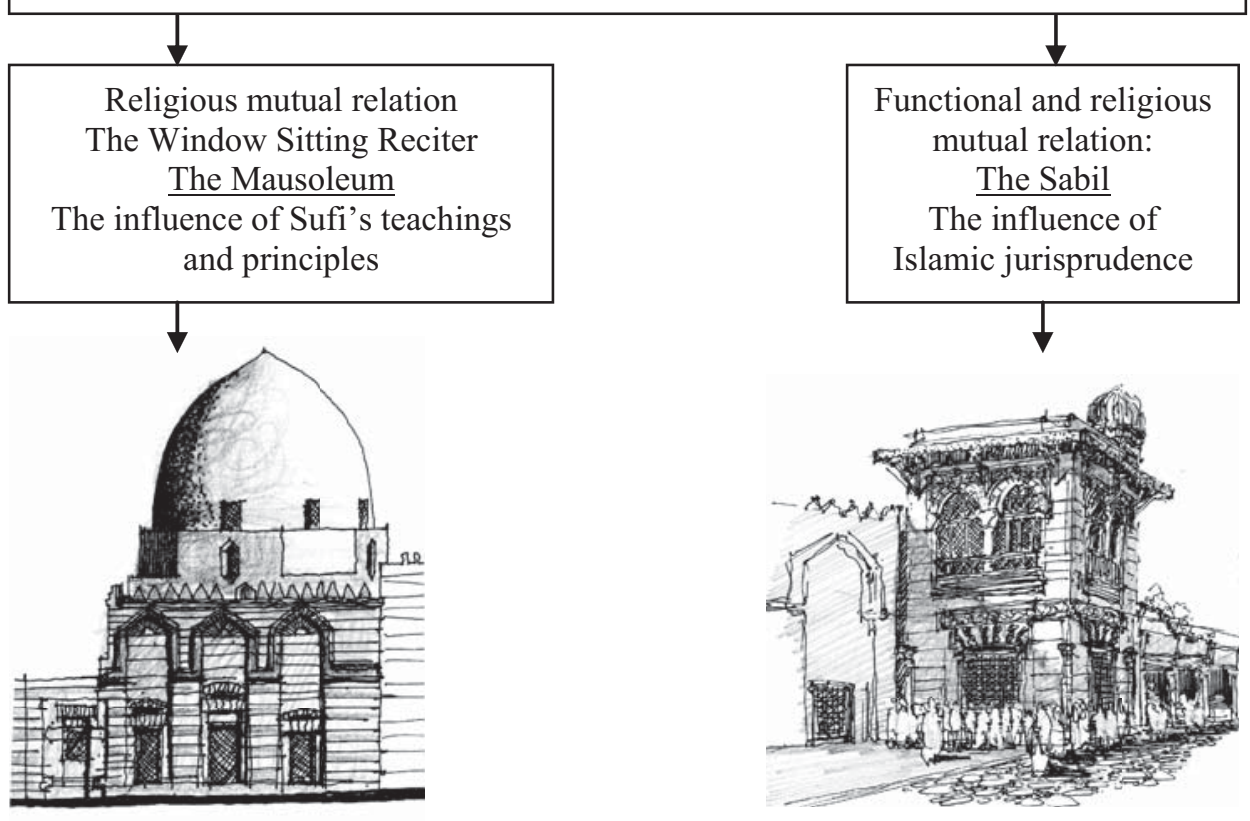

Figure 18: The two types of reciprocal relations created by top-down conventional decisions and Sufi principles.

space through the convention of the Window Sitting Reciter $[3,6,14]$. This relation mainly resulted from the desires of the elite or ruling class to be buried in the busiest place in the city centre after they died. Therefore they attached the grave or tomb to the complex that they built in the city. The design requirements or, specifically, the constraints of such a building meant exposure of the tomb or Mausoleum into the space and out of the building line. The reason for this was to create a reciprocal relation between the passers-by and the deceased. This reciprocal relation was traditionally conceptualised in the Sufi's convention of the Window Sitting Reciter. The mechanism of this mutual relation relied on the reciter, the man who was employed by the establisher of the complex and his descendants thereafter. This man would sit in the window of the tomb reciting the holy Qur'an and thereby allowing passersby to benefit from hearing the holy book and to pray for the deceased, a mutual benefit being derived. Therefore, the Mausoleum had to be located in an imposing position along the passageway (Figs. $19 \& 20$ ).

This relation was distributed between three parties: the first one is the establisher of the building, in this case the descendants of the deceased, the second party is the controller or the person(s) who runs the building and the third party is the users who use and benefit from the building. That means this type of urban fabric was under the dispersed model. On the one hand, this type was responsible for a social system called the endowment. This social system was responsible for producing such an urban development and was considered as the most preferable act of the elite. On this basis, the elite 


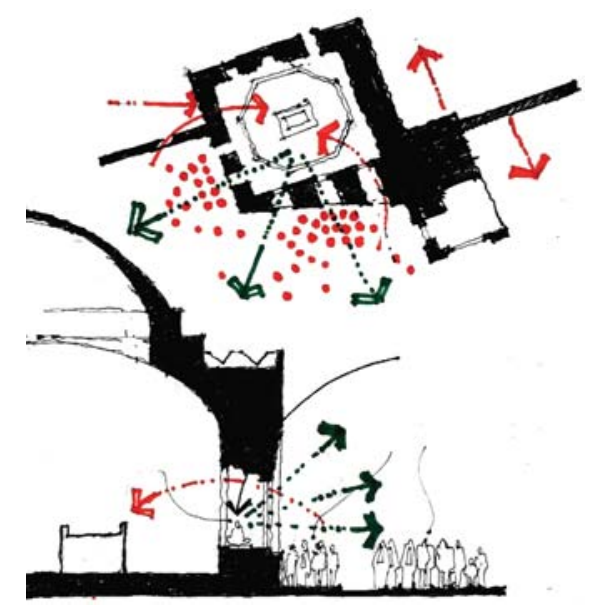

Figure 19: Mechanism of the convention of Window Sitting Reciter.

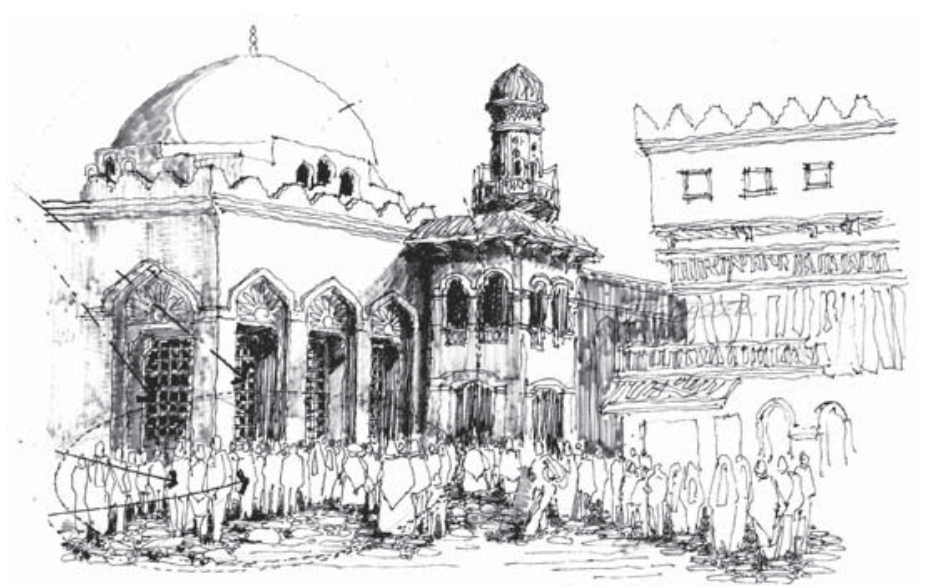

Figure 20: Showing the influence of the convention of the Window Sitting Reciter in the space of Bein El-Qasreen in front of the mausoleum of El-Saleh Ayyub on street life and the location of the mausoleum in relation to the space.

endowed buildings seeking to do good deeds for religious charitable purposes. On the other hand, this social system had a devastating impact on the urban context because it dispersed the responsibility between three different players, each of whom had their own interests and priorities. This devastating impact appeared clearly when the first generation of the builders died and the endowed building came under the control of another authority. This relation first crystallised in the $1250 \mathrm{~s}$ with the death of El-Sultan, the king, El Saleh Ayyub; his wife, the queen, wanted him to be buried in his complex in the city centre (Fig. 20) - the top-down conventional decision. Thus the mausoleum was attached later to the back of the complex. The tendency was to exposure the tomb onto the space as a way to signify the continuous power of the royal family as well as to comply with Sufi's beliefs, e.g. life after death and the integration of the two opponents, life and death, sky and earth. Thereafter, 


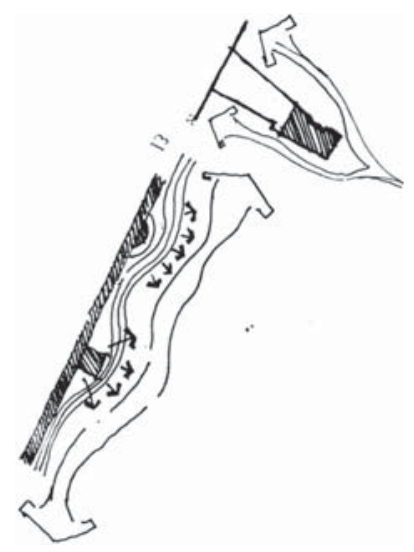

Figure 21: The dynamic shape of the building line.

this convention gained public appeal and validity and followers were encouraged to do the same, despite it being forbidden to build or to add any kind of graveyards within the city. It does, however, show how significant the influence of Sufism's principles and teachings on traditional society was.

4.2.2 The second mutual relation is the religious charitable purposes; interactive edges between the house of water, Sabil, and the passersby

As mentioned previously, this relation takes the form of building endowments, which means it was always under the dispersed model of responsibility. That was through using water feature inside space, which was considered as a fundamental aspect of Middle Eastern spaces in an arid and hot climatic region. That is because it was religiously desirable to provide water for the poor, whether they were residents or passersby, since they could not afford cisterns in their homes and it was a pious act for the elite to endow places for free drinking water [24]. This reciprocal relation was similar in its mechanism to the previous one of Window Sitting Reciter but different in its function and purpose and, of course, in its organising convention. Buildings were operationalised via wide windows along the ground floor and lots of people gathered in the front of these windows to drink. When people drank, they blessed and prayed for the erecter of the building or the endowment. The windows therefore had to be projected into the space; they could take a round or square shape and be projected off the building line without blocking the passageway (Fig. 21).

In addition, these buildings were elaborate and heavily decorated with verses from the holy Qur' an. While drinking, the passersby looked at the decorations and stopped to read. This meant that the spatial experiment changes from mobility to complete stopping. Increasingly often, the upper floor was a Kuttab, a school where children learnt how to recite and memorise the Qur'an. Such buildings were called Sabil (Fig. 22, a, b \& c). This type of building looks like the fountains used in public spaces in Western cities. It was attached to walls, not sited in the middle of the space [25], used not only for viewing but also for drinking. Therefore, these buildings were the common feature of urban spatial morphology in the Middle East (Fig. 22). The philosophical and symbolic convention behind this was the Sufi principles derived from the holy Qur'an: 'God created everything from water' Al-Anbi'a, Verse, 30. Whereas the functional ones was the avoidance of harm or no causing harm for the passersby that organized this relation via another convention, which is that the middle of space belongs to the passersby not to the fountain or Sabil, causing the building line to be movable and dynamic in shape. It was advisable not to put any obstacles in the passageway. 


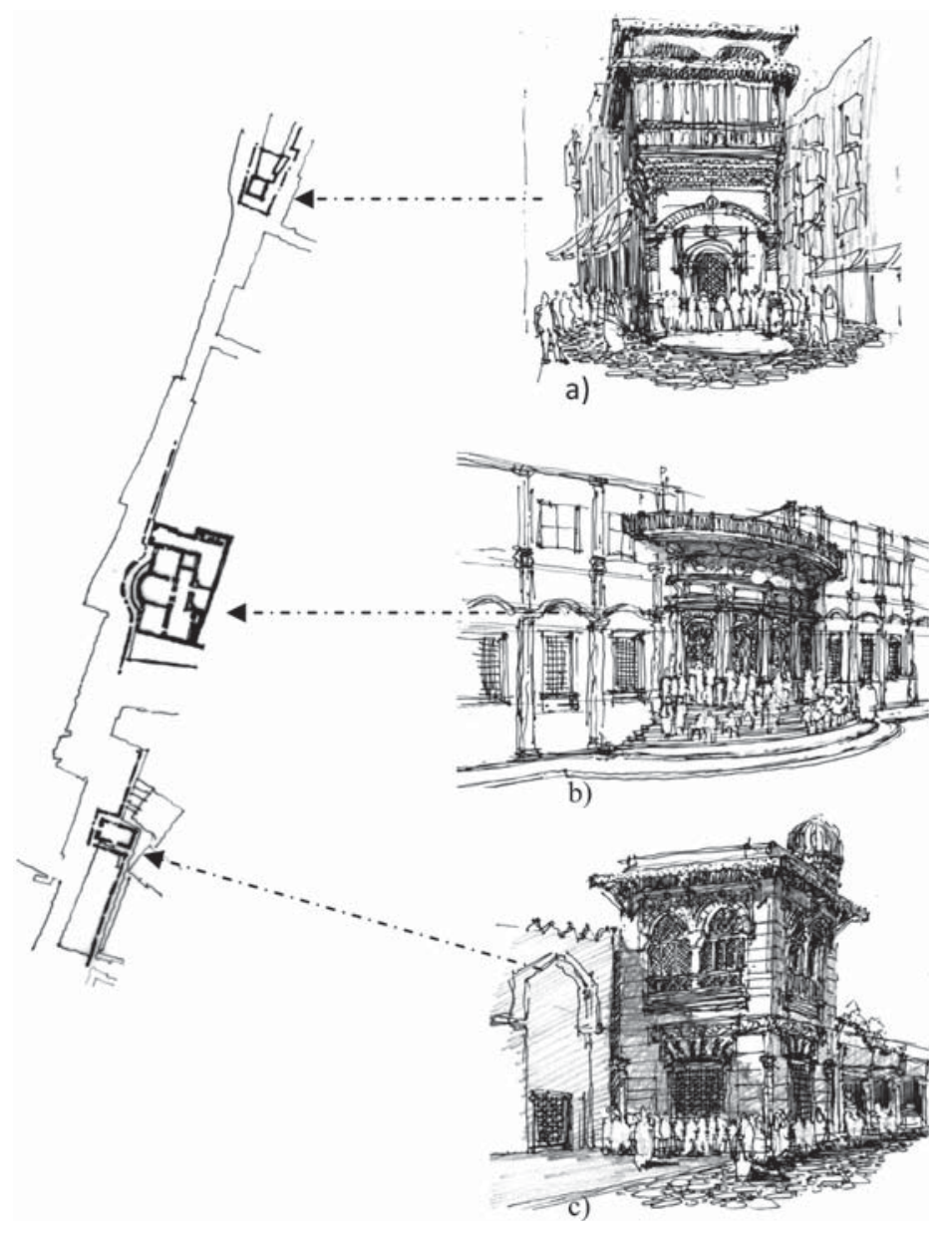

Figure 22: The Sabil was one of the obvious examples of the dispersed model. The ground floor has wide windows for people to refresh themselves, whereas the upper floor is a school for teaching children and orphans the holy Qur'an. a) Sabil Abd El Rahman Katkhouda, 1764. It was designed on a plateau in a way to allow people to queue in the front of the Sabil to avoid straddling the passageway. b) Sabil Mohammed Ali, 1838. It was designed on steps in the front of the Sabil that act as an fore-space for people to queue to avoid blocking the passageway. c) Sabil Khesrou Pash, 1535. It was designed on a plateau in a way as to allow people to queue in the front of the Sabil and to avoid blocking the passageway. The images are by the author.

\section{CONTRIBUTION, THE CONCEPT OF FINE-TUNING}

It is important to mention that the aim of developing this model is not to suggest that the traditional responsibilities should be applied today but rather to draw attention to their qualities and how they applied a spontaneous holistic approach of sustainability to achieve a socially responsible environment. Increasingly, the failure of the contemporary environment has aroused the concern of architects and planners, and many have turned to the traditional built environment for an answer. For example, 
many Western writers referred to that the liveability of street life of many traditional American cities gradually destroyed due to the overwhelming of new technologies, economic forces, regional decentralization and federal policies [26]. Furthermore, Douglas Rae, the political scientist, argues that city planners cannot recreate such an old urbanism but they may improve the contemporary cities by understanding and remaking the best features and the lessons that can be inferred from [27]. Therefore, the most important lesson that can be taken from the examination of traditions in the Middle Eastern urban spatial morphology is conceptualised in this form of 'pattern language' that organised both social and urban life, synthesising them in a unified framework in a way that manifested ideologies and paradigms and their implication for the physical form of the city. Additionally, the development of such a model in the form of a reflective and exploratory process will enable us as researchers and professionals to rationalise the built environment to bring order into the events of nature. In other words, this pattern language approach has been reconceptualised in a way that allows for better understanding and deeper interpretations of urban morphology and its evolution over time; it offers a lens through which the architect or urban designer can view the built environment differently [6].

Generally, the components of the approach, the mechanism of decision making, the responsibility, and its tool, the conventions, play a salient role in achieving a balance between the two parties in the built environment; the authority and the individuals of the communities. These parties worked together, creating an integrated decision at two levels; top-down decisions are responsible for regional unity or homogeneity, and bottom-up decisions provide diversity and uniqueness and local identity through considering the localised community-based customary rules. On the one hand, such a bottom-up decision making is the salient catalyst of tactical moves that maintained the social sustainability of the built environment in the Middle East. In addition, it draws lines whereby top-down decisions must give way to allow opportunity for processes of bottom-up self-organisation to take place. The approach presented here has revised our perspective on the role of centralised laws and meta-principle conventions that do not always erode and overtake the localised customary rules and practices at the micro scale of the building process but sometimes they integrate and enhance the local conventions to maintain national identity.

\subsection{The professional discipline, the concept of fine-tuning}

In more detail, this approach has built up and manifested how the mechanism process of top-down and bottom-up was operationalised in the light of Akbar's models of responsibility. It explores how the changes in these models caused significant changes in the spatial urban morphology so that it is conceptualised in the concept of fine-tuning of the urban form. This fine-tuning is to do with management, occupancy and control of spatial urban morphology. Therefore the major contributions of this concept apply to both the professional and academic disciplines. For the former, this concept contributes to the design and conservation process of spatial urban morphology. It provides the essential base of knowledge for professionals who have responsibility for conservation and management in the built environment, such as architects and urban designers. For example, when dealing with spatial urban form, the concept of fine-tuning goes through two phases: the first phase is documentation and analysis of responsibility models and their conventions; the second phase is the proposed intervention solution or action in the built form.

5.1.1 Documentation and analysis of responsibility models and their conventions

The first step according to this proposed approach is to investigate the different responsibility models that exist in that specific urban context along with different parties. The second step is to analyse 
and document the potential of sustainability that has already been achieved in the space and which model(s) was responsible. Meanwhile, we have to document the defects that hinder this sustainability and compatibility and identify the responsibility model(s) that was responsible as well. The third step is to determine the location, physically, at which the potentials and defects occurred.

5.1.2 The second phase is the proposed intervention solution or action in the built form

Then the concept of fine-tuning of urban form starts to become as an advanced level of the diagnostic process and the anatomic analysis of the space [3,6]. That is before we start to think about other drastic solutions or treatments for the spatial form such as demolishing or replacing different parts. Thus the concept of fine-tuning, based on the previous investigation of spaces in terms of responsibility models, starts to change the defective models of responsibility or changes some responsibility models into others. In other words, it gives more rights to some groups of users and withdraws some rights from other groups of users in the same space. For example, when the permissive model of a group of shop owners is changed into a unified model - giving them more power and ownership of the areas in front of their shops - that means they have the right to display their products outside their shops, to add or remove parts of their facades for more exposure to the space provided that no harm is caused to the passersby.

Consequently, this part of the space will be changed from just shop windows into movable active shop frontages or, to put it another way, into interactive spatial edges in the form of traditional shops, moveable interactive edges. In that case, the avoidance of harm plays a crucial role via two conventions; the first one allows the shop owners and local residents the freedom to act or build in the horizontal or vertical dimensions of the space provided they do not block the space visually, orally or physically. The second allows passersby the freedom to use the space and to exercise their rights properly without abusing others' rights. This is in addition to the right of objection by the passersby to any harmful act of from the vendors or shop owners.

In other parts where some defects have been noticed, in market places, for example, the fine-tuning concept changes the tone of these areas by converting their fully possessive model into a limited possessive model or permissive or trusteeship models. That means the central authority takes control over the market places in view of the harm that vendors may cause to the passersby or because of disputes between them. Then the area of the passageway will be widened, and vendors in this space are allowed to mark their areas freely and control their spaces; the key convention is that of the right of utility which is the priority of vendors who were first to utilise and claim a specific area in the market place to display their products without blocking the passageway. The convention of the passersby is still the same; freedom to use the space and to exercise their rights properly without abusing others' rights. This is in addition to the right of objection by the passerby to any harmful act of the vendors, then repeating the same pattern in the other parts of the space. The fine tuning concept deals with these parts according the potentiality or negativity of these parts towards achieving responsive built form. Thus, models can be changed from unified to trusteeship models, whereas others may be changed from dispersed models to permissive models, etc.

\subsection{The academic discipline}

In the academic field, this approach contributes to the urban and architectural education process by providing an essential knowledge and a base for site analysis, upgrading and conservation of valuable contexts. At the level of urban planning, the approach has provided lessons in the design objectives of urban planning education. Also, it highlights that flexible designs that comprehensively fulfil the users' needs are more beneficial than those that incorporate rigid design or fixed functions. It is 
increasingly helpful to create built environments that are ecologically and climatically compatible, healthy and safe. Contemporary schools of architecture and urban planning also recognise the need to widen the scope of study to include in the use of space, traditional societies' principles such as the avoidance of harm, the maintenance of ownership rights and the maintenance of private and semiprivate spaces such as cul-de-sacs and ante-spaces in residential and commercial areas, highlighting the efficiency and economic advantages of traditional systems. These advantages result from conferring more power to community members to protect their built environment from deterioration.

On the architectural and urban levels, lessons from the past instruct us how to build within contemporary forms. It is challenging to integrate the two controversial issues of unity and uniqueness to create a durable urban character that does not directly copy from the past. In other words, planners should consider how to express local identity in contemporary building types and functions. Furthermore, the urban fabric must express the inherited traditions that provide continuity and have been taken up in the community's vocabulary.

However, one of the drawbacks that this approach has been confronted is the lack of sources that describe in more details the urbanism of local people. Since the vast majority of documented cases from medieval ages focus on the historic centres that were always reformed by the official urbanism or buggier urban grains and considered as the guidelines or pilot projects for the medieval city ignoring by accident the filling of urban form which is the urbanism of local people. That is because the majority of historic documents that have been reached to our hands focused on this top-down urban forms or iconic buildings with its extension to some urbanism of local people that always attached to the margins of any historic centres with little to contribute to the building process of the public. In other meaning, sources of bottom-up or the filling of urban fabric in the traditional eras is so rare and the documented cases depended on the few situations that recorded personally by judges in courts and disputable councils. But the majority of cases were unrecorded or written. Additionally, it has been observed that most written or recorded cases are concentrated on one country rather than the other Middle Eastern cities, such as Tunisia as its Judge, Ibn El-Rami who lived in the end of 14th century, was keen to record all these cases whereas that was not the case in other countries. That means some cases must be measured according to the criteria of the documented ones with slight marginal differences.

What is more, one of the main sources and analytical tools of this approach is the orientalists' paintings of those who visited the Middle East in the 18th and 19th centuries and illustrated its traditional life and urbanism. However, the analyses of these paintings had been illustrated wrongly a considerable number of conventional building relations tending to correct the perspective views or angles visually. That is because they did not recognize the philosophical base behind these conventional regulations. Consequently, these paintings illustrated incorrectly some building's relation that had never been subjected to any of the traditional conventions that were ever followed.

The future research plan suggests that this approach can bring better understanding to other cultural contexts, particularly Western culture like Latin urban morphology through a modified form of this pattern language. This modified form can be built upon the idea of similarities of paradigms of the two cultures. One of these key similarities can be touched in the ethical values and ideologies behind traditional urban fabric in both sides.

\section{CONCLUSIONS}

It has been argued that too much top-down decisions stifle and squeeze opportunities for localised territorial expression, whereas too much bottom-up decisions run the risk of degenerating into territorial disputes, the victory of the loudest voices. Therefore, 'pattern language' brings together the ideological dimension of a city's inhabitants and the physical characteristics of urban morphology in 
an unified frame work which may help urban designers, architects and professionals who have responsibilities for spatial conservation and management to see and understand the structure of urban form in new ways. These ways can reveal something significant about the relationship between spatial organisations and the way by which buildings and spaces are used and controlled, through different urban and building conventions and their potential to deliver socially responsive, friendly, and sustainable built environments. What is more, macro-level decisions made by the authority or the meta-principles require citizen's input as part of democratic strategy. This will be through the integration between policies, the right of control, the right of ownership and the right of use for different parties on different scales, planning, urban, and architectural, that can be conceptualised in the

fine-tuning of urban form or responsibility distribution. It is necessary to create a socially responsive built environment by investigating the responsibilities of different parties on these different scales and their impacts on the nature of the process of decision making, whether localised community customary rules, bottom-up or meta- principle role, top-down. Therefore, the principles and lessons of the mechanism of decision making from traditional Middle Eastern culture may be applied, in a modified form, to bring more social responsiveness and sustainability to our contemporary built environments.

\section{REFERENCES}

[1] Alexander, C., Ishikawa, S., Silverstein, M., Jacobson, M., King, F.I. \& Angel, S., A Pattern Language, Oxford University Press: New York, 1977.

[2] Akbar, J.A., Responsibility and the Traditional Muslim Built Environment (Doctoral Dissertation), Retrieved from Massachusetts Institute of Technology, Department of Architecture, website:http://mit.dspace.org/handle/1721.1/15572, 1984.

[3] Mohammed, G. \& Thwaites, K., The role of ideological dimension in developing an anatomical approach to urban morphology: exploration of a new analytical method of open spaces network. Proceedings of the conference on The Sustainable City VI, Sixth International Conference on Urban Regeneration and sustainability, A Coruna: Spain. 14-16April 2010. [Online]. Available For http://library.witpress.com/pages/PaperInfo.asp?PaperID=20831 [Accessed 14th April 2010]. WIT Transactions on Ecology and the Environment, Vol.129, ( 2010 WIT Press.

[4] Carr, S., Francis, M., Rivilin, G.L. \& Stone, M.A., Public Spaces, Cambridge University Press: Cambridge, 1992.

[5] Akbar, J., Imarat al Ard fi al-Islam, 3rd ed. (in Arabic), Muassasat ar-Risalah Press: Beirut, 1998.

[6] Mohammed, G. \& Thwaites, K., An exploratory and reflective process of urban spatial morphology within social sustainability: lessons from middle eastern islamic tradition. Digest Middle East Journal, 19(2), pp. 249-267, 2010. doi:http://dx.doi.org/10.1111/ j.1949-3606.2010.00033.x

[7] AlSayyad, N., Biyn Al-Qasriyn: The street between the two palaces. Streets: Essays in Urban History, eds Z. Celik, D. Favro, \& R. Ingersol, University of California: Berkeley, 1995.

[8] Akbar, J.A., Rationality: the blight of the muslim environment. Architectural Knowledge and Cultural Diversity, ed. W. O’Reilly, Comportements: Lausanne, 1999.

[9] Mohareb, N.I., Land use as a sustainability indicator for Arab cities. Proceedings of the Institution of Civil Engineers, Urban Design and Planning, (DP3): pp. 105-116, 2010.

[10] Habraken, N.J., The Structure of the Ordinary, M.I.T press: London, 1998.

[11] Hakim, B.S., Arabic-Islamic Cities: Building and Planning Principles, Kegan Paul International: London, 1986. 
[12] Lawrence, D.L. \& Low, S.M., The built environment and spatial form. Annual Review of Anthropology, 19, pp. 453-505, 1990. doi:http://dx.doi.org/10.1146/annurev.an.19.100190.002321

[13] Fox, W., A Theory of General Ethics: Human Relationships, Nature and the Built Environment, MIT Press: Cambridge, Massachusetts, 2006.

[14] Mohammed, G. \& Thwaites, K., The role of urban and planning conventions in reforming urban spatial morphology within social sustainability. 21st IAPS conference, Vulnerability, Risk and Complexity: Impacts of Global Change on Human Habitats, Leipzig, Germany, 2010.

[15] Hakim, B.S., Generative processes for revitalizing historic towns or heritage districts. Urban Design International, 12(2-3), pp. 87-99, doi:10.1057/palgrave.udi.9000194.2007.

[16] Hakim, B.S., The "Urf" and its role in diversifying the architecture of traditional Islamic cities. Journal of Architecture and Planning Research, 11, pp. 108-127, 1994.

[17] Hakim, B.S., Reviving the rule system: An approach for revitalizing traditional towns in Maghrib. Cities, 18, pp. 87-92, 2001. doi:http://dx.doi.org/10.1016/S0264-2751(00)00060-3

[18] Grant, J., The dark side of the grid: power and urban design. Planning Perspectives, 16, pp. 219-241, 2001. doi:http://dx.doi.org/10.1080/02665430152469575

[19] Carmona, M., Heath, T., OC, T. \& Tiesdell, S., Public Places-Urban Spaces: the Dimensions of Urban Design. Architectural Press, An imprint of Elsevier Science: Oxford, 2003.

[20] Zarabozo, M.J., Commentary on the Forty Hadith of Al-Nawawi, Introduction by Jaafar Sheik Idris, Boulder, Al-Baheer Company for publications and translations: USA, 1999.

[21] Roberts, D., (1796-1864), Bazaar of the Coppersmiths. "The central space of Islamic Cairo", Retrieved January 3, 2010, from http://www.museum-tours.com/museum/roberts/roberts0.htm

[22] Coste, P.X., (1787-1879). Litho, exterior of the Mosque of Qalaoun, Cairo. bridgeman, Art and Culture History. Retrieved, from http://www.bridgemanart.com/, 2010.

[23] Cairo at the end of 19th Century, www.egyptedantan.com.

[24] Antoniou, J., Historic Cairo: A walk through the Islamic city, American University in Cairo Press: Cairo, 1998.

[25] Sitte, C., City Planning According to Artistic Principles, Phaidon: London, 1965.

[26] Simon, D., Understanding and making places in the city: integrating the urban visions of christopher alexander and bill hillier. Interdisciplinary Design and research e-Journal (IDRP), [on-line http//www.idrp.wsu.edu/], 2, pp. 1-8, 2008.

[27] Rae, D.W., City: Urbanism and Its End, Yale University Press: New haven, 2003. 